\title{
México, ¿Hacia la consolidación de un modelo de igualdad de oportunidades para una sociedad fragmentada?
}

\author{
Miguel Ángel Vite Pérez*
}

\section{Resumen}

Este ensayo tiene como propósito la construcción de explicaciones acerca de los fundamentos de la asistencia social estatal dirigida a la atención de una parte de los grupos sociales vulnerables, en un contexto de crisis del modelo de la igualdad de posiciones y su sustitución por el modelo de la igualdad de oportunidades, donde lo más importante son los méritos individuales. Esto permite estudiar el asistencialismo estatal mexicano y su impacto en la reproducción de una sociedad fragmentada, que se caracteriza por la existencia de situaciones de excepción y vulnerabilidad.

\begin{abstract}
The purpose of this essay is the construction of explanations about the basis of public welfare programs in the context of the crisis of the model of equal positions and its replacement by a model of equality of opportunities, where individual merits play a central role. This allows the study of the Mexican welfare state and its impact on the reproduction of a fragmented society, characterized by the existence of exception situations and vulnerability.
\end{abstract}

Palabras clave: igualdad de posiciones, igualdad de oportunidades, vulnerabilidad, dispositivo del bienestar, sociedad fragmentada..

Keywords: equality of positions, equality of opportunities, vulnerability, welfare apparatus, fragmented society.

* Doctor en Sociología por la Universidad de Alicante, España y profesor-investigador del Centro de Investigaciones Económicas, Administrativas y Sociales (CIECAS) del Instituto Politécnico Nacional. Miembro del Sistema Nacional de Investigadores, nivel 2. 
presente ensayo tiene como objetivo la elaboración de interpretaciones sobre el significado sociológico de los programas estatales mexicanos de transferencias condicionadas que están dirigidos a una parte del universo de los vulnerables, éstos son definidos desde el poder político como pobres extremos, aunque en realidad, son resultado de la crisis de la sociedad del trabajo.

A lo largo de las últimas décadas, la crisis de la sociedad del trabajo se ha manifestado como un aumento del empleo precario y al mismo tiempo, del desempleo permanente caracterizado por una ausencia de protecciones sociales, que se derivan de la existencia o presencia de un sistema estatal de bienestar. Sin embargo, el trabajo precario se caracteriza por una relación laboral inestable e irregular, con contratos por tiempo limitado y sin garantía de estabilidad porque existe una desprotección legal de parte del Estado (Neffa, 2010). La desprotección legal estatal de tipo laboral abarca las actividades económicas informales, por lo tanto, el trabajo precario se incluye tanto en el empleo informal como en el trabajo no registrado (Neffa, 2010: 17-24). Por otra parte, en las últimas décadas la generalización del empleo precario ha provocado un rápido incremento de las tasas de empleo informal que, al menos en América Latina, son del 50 por ciento, es decir, por cada persona que tiene un empleo formal hay otra que está ocupada en un trabajo precario definido por los bajos ingresos y la ausencia de seguridad social (Elías Salazar, 2013: 15).

En este sentido, la vulnerabilidad social es un proceso caracterizado por la ausencia de derechos sociales para los trabajadores precarios y desempleados que multiplica diversas situaciones de inseguridad caracterizadas, desde un punto de vista general, por los riesgos desprendidos de la crisis de la sociedad asalariada. Éstos atentan contra la reproducción física, cultural y social de los grupos que han dejado de pertenecer a la esfera de la inclusión social definida por un empleo formal, donde son válidas las protecciones o derechos sociales (Elías Salazar, 2013: 64).

Este ensayo parte del supuesto de que los diferentes puntos de vista teóricos sobre la vulnerabilidad social son utilizados para construir explicaciones de un hecho particular que adquieren una existencia propia y que se observan mediante algunas de sus manifestaciones particulares (Reed, 2011: 1-13). Las interpretaciones realizadas acerca de los hechos específicos analizados son producto de una combinación de circunstancias parti- 
culares que posteriormente se transforman en tendencias generales, sobre todo cuando se presentan en las diferentes sociedades (Reed, 2011: 20-21). Una de ellas es la vulnerabilidad social que se puede analizar mediante la utilización del modelo de la igualdad de posiciones y de la igualdad de oportunidades donde la intervención del Estado, organizada a través de las protecciones sociales, ha desaparecido en un contexto de crisis de la llamada "sociedad del trabajo".

El modelo de la igualdad de posiciones está vinculado con la organización estatal identificada con el Estado de bienestar, mientras que el de la igualdad de posiciones es el resultado de la desvinculación paulatina del bienestar social del trabajo asalariado que, en consecuencia busca la individualización del bienestar que se debe lograr a través del desarrollo de las capacidades y habilidades individuales adquiridas por una formación escolar, lo que ha terminado por justificar una desigualdad social basada en la meritocracia.

El ensayo se divide en seis partes. En la primera se revisan de manera general los supuestos de los modelos de la igualdad de posiciones y de la igualdad de oportunidades para conocer sus diferencias y observar, a su vez, el impacto de la crisis del Estado de bienestar, que es favorable al establecimiento y consolidación del segundo modelo en una sociedad individualizada. En la segunda parte se analiza la existencia de un dispositivo particular del bienestar social promovido por el Estado neoliberal que busca atender a un sector de los vulnerables, los cuales son definidos como pobres extremos. En el tercer apartado se elabora un análisis general del significado de los programas de transferencias condicionadas en la conformación de nuevos comportamientos entre las familias beneficiadas. En la cuarta parte se estudia la presencia del modelo de la igualdad de oportunidades en los programas de asistencia social focalizada en México. En la quinta sección se destaca que los programas mexicanos de asistencia social focalizada influyen en la reproducción de una sociedad fragmentada cuya característica principal es un acceso diferenciado a los mecanismos de inclusión social. Finalmente, se presenta una reflexión general acerca del tema de estudio del presente ensayo.

\section{De la igualdad de posiciones a la igualdad de oportunidades}

En el capitalismo postindustrial, la crisis de la sociedad del trabajo generó un desplazamiento del modelo de la igualdad de posiciones por el de la igualdad de oportunidades, principalmente porque el trabajo asalariado 
dejó de ser el principal generador de derechos sociales o protecciones sociales (Castel, 2010). No obstante, las protecciones sociales, consideradas como derechos sociales, fueron administradas o gestionadas por un sistema de bienestar estatal. Es decir, por un Estado interventor en la administración del bienestar colectivo que en algunas sociedades desarrolladas dio como resultado un Estado de bienestar (Swaan, 1992; Offe, 1990; EspingAndersen, 1993; Sotelo, 2010). Un Estado de bienestar que realizó esfuerzos para cumplir con los objetivos de universalización de las prestaciones sociales, consideradas también como parte de los derechos ciudadanos (Marshall y Bottomore, 1998; Pisarello, 2007). Posteriormente, la integración de los derechos sociales a la ciudadanía fue resultado de la transformación de las necesidades humanas en derechos ciudadanos (Doyal y Gough, 1994; Montagut, 2004).

Por otro lado, el trabajo asalariado como fuente de derechos sociales reforzó la creencia de que la igualdad de posiciones se basaba en políticas de redistribución con un impacto en la disminución de las desigualdades sociales (Díaz-Salazar, 2011). En este caso, el modelo de la igualdad de posiciones estuvo centrado en la reducción de las inequidades sociales entre las diferentes posiciones, mientras que la intervención estatal fue para garantizar el bienestar de los que ocupaban las posiciones más frágiles (Castel, 2004a; Dubet, 2011: 21).

La crisis de la sociedad del trabajo no sólo se manifestó como una expulsión masiva de población del mercado de trabajo, sino como una expansión de la vulnerabilidad entre los contingentes que dejaron de tener derechos sociales por su nueva condición de subempleados y desempleados (Castel, 1995: 27-36). En consecuencia, la vulnerabilidad social también conlleva el debilitamiento de los lazos de cohesión o pertenencia a una sociedad, interpretada desde un punto de vista conservador, como la causa del aumento de las actividades criminales entre los pobres (Wacquant, 2000; Saraví, 2009: 21). Sin embargo, la igualdad de posiciones no significó una igualación de ingresos, sino una universalización en el acceso a bienes y servicios porque fueron considerados como derechos sociales y no como mercancías (Esping-Andersen, 1993: 71; Castel y Haroche, 2003: 27).

Otra característica del modelo de igualdad de posiciones fue su alta capacidad de inclusión social al garantizar los derechos sociales para los ocupantes de las diferentes posiciones (Castel, 2004b: 55-86). De esta manera, la solidaridad promovida por el modelo de igualdad de posiciones 
fue "orgánica"1 porque estaba basada en la integración de las diferentes actividades o tareas laborales mediante los programas estatales de bienestar, considerados como una condición de igualación entre las diferentes posiciones (Castel, 2004c).

De acuerdo con lo expuesto, la crisis del Estado de bienestar también puede considerarse como una crisis del modelo de la igualdad de posiciones, que a través de las políticas sociales buscaba atender las necesidades humanas de los integrantes de una sociedad, pero insisto, porque eran derechos ciudadanos (Doyal y Gough, 1994: 33-34).

Desde un punto de vista general, la configuración de un Estado neoliberal (Gowan, 2000: 239-316; Steger y Roy, 2011: 17-43) favoreció el establecimiento de un nuevo modelo de organización social que se identificó más con el de la igualdad de oportunidades (Delcourt, 2010: 7-11).

Al tener como uno de sus objetivos la disciplina fiscal, el Estado neoliberal afectó los niveles de protección social provocando una mayor vulnerabilidad social, ésta se reflejó en el aumento de la precariedad laboral, es decir, trabajos de bajos salarios y con escasas o nulas protecciones sociales (Sorensen, 2011: 59-61). Así fue como el modelo de la igualdad de posiciones intentó resolver una contradicción permanente en las sociedades democráticas liberales: la igualdad formal de sus ciudadanos y las desigualdades sociales reales creadas por la economía capitalista (Dubet, 2000; Polanyi, 2003). Sin embargo, el modelo de la igualdad de oportunidades tampoco resolvió la contradicción mencionada mediante el establecimiento de la meritocracia. Ésta fue considerada como la única vía para combatir los privilegios heredados al suponer lo siguiente: todos los integrantes de una sociedad se encuentran distribuidos de manera proporcional en la estructura social sin importar sus orígenes socioeconómicos, lo que facilitaría una mayor movilidad social (Collins, 1989; Torche, 2010).

Desde el modelo de la igualdad de oportunidades, ${ }^{2}$ las desigualdades sociales son justas porque están basadas en los méritos de los individuos y no en la endogamia de las organizaciones que no representan los intereses de las minorías (Dubet, 2011: 55). En el modelo de la igualdad de posiciones, las desigualdades sociales se definen por las diferentes posiciones ocupadas y en menor medida por los méritos de los individuos

1 Una solidaridad basada en la división social del trabajo donde las desigualdades son percibidas como funcionales en el sistema económico y no como el origen de la desigualdad social, que es resultado de una distribución inequitativa de la riqueza (Véase Durkheim, 1993).

2 El modelo de la igualdad de oportunidades intenta integrar a través del control y la coordinación de comportamientos de los sujetos que poseen los méritos para competir por una mejor posición en un contexto de escasez de trabajo asalariado protegido (Véase Honneth, 2009: 255). 
(Dubet, 2000: 30). ${ }^{3}$ Sin embargo, en la sociedad organizada por el modelo de las oportunidades, las injusticias sociales obedecen a la inexistencia de equidad en los procedimientos de selección, lo cual habría que corregir mediante políticas que garantizaran una competencia equitativa (Dubet, 2011: 59; Banerjee y Duflo, 2011). Por último, cabe recordar que el modelo de la igualdad de oportunidades ha justificado la existencia de programas de asistencia estatal destinados a grupos con carencias particulares donde sus deficiencias y privaciones les han impedido, supuestamente, tener una mayor movilidad social (Rifkin, 2010: 193-216; Simmel, 2011:87).

\section{El dispositivo ${ }^{4}$ del bienestar social}

El bienestar social está configurado por un conjunto heterogéneo de elemen$\operatorname{tos}^{5}$ articulados mediante las políticas sociales. Esto significa que el bienestar social es una de las estrategias de poder que sirven para gestionar algunas de las necesidades y carencias de los grupos que no han podido colocarse en una situación de igualdad de oportunidades (Esping-Andersen, 2001: 92).

La organización de un sistema de bienestar social se basó en un aparato de estado, es decir, en instituciones especializadas que justificaron su presencia a través de la ideología de la justicia social. La noción de aparato de estado hace referencia a la dominación de una clase privilegiada sobre una no privilegiada, apoyada por una ideología particular (Althusser, 2011: 114-115). Sin embargo, esta consideración dificulta su uso debido a que existe un sesgo clasista que supuestamente está presente en las diversas instituciones que integran el orden social. No obstante, desde mi punto de vista resulta útil, cuando se considera que el aparato de estado es un conjunto de instituciones reales y concretas que se explican más por

3 “(...) ahora la desigualdad económica se presentaba cubierta con un manto de legitimidad prácticamente incontestable por los reformistas igualitaristas, ya que lo que convertía a las desigualdades del viejo régimen en intolerables era la arbitrariedad, mientras que ahora éstas provenían de la desigualdad de talentos y ambición, cuya distribución entre la población no obedecía al favoritismo político, sino a una combinación moralmente irreprochable de suerte y de elección. La desigualdad pasaba a ser el producto inevitable del éxito y el fracaso individual merecidos" (Puyol, 2010: 31).

4 "El término "dispositivo" aparece en Foucault en la década de 1970 y se utiliza inicialmente para designar operadores materiales del poder, es decir técnicas, estrategias y formas de sujeción introducidas por éste (...) por definición éstos son de naturaleza heterogénea: se trata tanto de discursos como de prácticas, de instituciones como de tácticas móviles (...)” (Revel, 2009: 52).

5 Estos elementos no sólo tienen que ver con las necesidades humanas, sino con las acciones particulares que los diferentes estados establecen para su satisfacción; por ejemplo, mediante la utilización de mecanismos desmercantilizadores (Le Grand, 2001: 33). 
las prácticas y ejercicios de poder que si aparecen en el concepto de dispositivo (Foucault, 2009).

En este caso, las nociones de dispositivo y aparato de estado tienen en común lo siguiente: aluden al poder y a sus estrategias de reproducción que no solamente ocurren a través de la ideología, sino mediante el control de la vida humana (Mendiola 2009: 33). La definición de dispositivo hace referencia a una relación de poder, donde el saber y la subjetividad permiten la gobernabilidad de los individuos (Braunstein, 2012: 70).

El dispositivo del bienestar social fue el Estado de bienestar que impactó en el comportamiento de los beneficiarios y fortaleció, al mismo tiempo, el discurso de la justicia social (Ceballos, 2005: 84-85; Herrera y Castón, 2003). Desde otro punto de vista conceptual, los aparatos son visualizados por su capacidad para capturar parte de la existencia humana; sin embargo, se encuentran separados de la misma porque son administrados por el poder al modelar y controlar algunos de los comportamientos sociales (Agamben, 2009: 13-15; Silveira y Rivera, 2009). Por su parte, Braunstein (2012: 28-29) utiliza la noción de servomecanismo - misma que hasta cierto punto resulta similar a la idea de aparatos de Agamben-que alude a un instrumento que le sirve a los usuarios, y a su vez, los hace siervos de sus procedimientos y limitaciones. En otras palabras, los servomecanismos son extensiones y también reguladores del funcionamiento del cuerpo humano.

Las reflexiones anteriores permiten destacar que la sociedad organizada, bajo el modelo de la igualdad de posiciones, fue una sociedad disciplinaria, caracterizada por la organización del trabajo asalariado mediante el modelo de producción fordista, donde las posiciones laborales estaban garantizadas por la organización estatal del bienestar universal (Navarro, 2000). Cabe destacar que los aparatos y los servomecanismos son máquinas informáticas que regulan la producción y el consumo a través de una red donde no hay tacto ni vista y las ganancias o utilidades se depositan en cuentas automáticas, creando una identidad personal que se pone en acción mediante contraseñas o tarjetas de plástico, que también han sido utilizadas para canalizar la ayuda estatal orientada hacia sus beneficiados (Braunstein, 2012: 185-186; About y Denis, 2011).

En la sociedad de la igualdad de oportunidades, los aparatos y los servomecanismos son instrumentos tecnológicos que se han identificado con la creación del bienestar individual, mientras que los dispositivos en la sociedad de la igualdad de posiciones buscaron la universalización de las protecciones sociales para disminuir las situaciones de riesgo provenientes de la dinámica económica capitalista (Adelantado, Noguera y Rambla, 2000: 28). Adicionalmente, la igualdad de oportunidades se ha transformado en 
el objetivo estatal de los programas de transferencias condicionadas que han obligado a los individuos beneficiados a recibir una ayuda limitada para superar algunas de sus carencias.

Para concluir, en el modelo de la igualdad de oportunidades, la vulnerabilidad social no se debe a la falta de empleo remunerado ni a la ausencia de derechos sociales, su razón se basa en la no existencia de capacidades individuales adquiridas en el sistema formal de educación (Griffin, 2001: 26-27; Castel, 2001: 39; Peña, 2010: 56-57).

\section{El modelo de transferencias condicionadas}

El Estado neoliberal creó los dispositivos mercantiles en el bienestar colectivo, convirtiendo a los ciudadanos parcialmente en clientes o consumidores y a algunos de los pobres en sujetos de asistencia o ayuda focalizada para supuestamente superar algunas de sus carencias relacionadas con su limitada capacidad para generar ingresos y consumo. Del mismo modo, para rehacer la solidaridad entre los pobres convertidos en sujetos de la asistencia estatal, se estableció un esquema organizativo identificado con el capital social que fomentaría el compromiso cívico, transformado en la base del mejoramiento de las condiciones de vida de la comunidad o grupo (Putnam, 2003: 10).

Considero que fue una manera de introducir, bajo los programas gubernamentales de transferencias condicionadas en los países subdesarrollados, nuevas formas de organización para que los beneficiarios cumplieran con los propósitos de cohesión social cuando intervenían en la realización de obras colectivas. Sobre todo cuando la acción estatal había dejado de ser un derecho ciudadano para transformarse en una responsabilidad compartida entre el mercado, el individuo y la comunidad (Field, 2003: 12-13).

En este sentido, los programas de transferencias condicionadas para algunos grupos de pobres se han enfocado más a la atención de necesidades definidas por el nuevo modelo de la igualdad de oportunidades como la educación, alimentación y salud (Cogco, Rodríguez y Pérez, 2011). Por otro lado, la introducción de la racionalización económica en el gasto social, al menos en América Latina a fines de los años ochenta del siglo XX, fue favorable a la focalización de la política social, sostenida en la creencia de que los ingresos públicos o estatales son escasos y por tal motivo se deberían de gastar sólo en lo programado (CEPAL, 1995: 13-15). Otra manera de justificar la eficiencia de los programas estatales de ayuda focalizada fue a través de la utilización de instrumentos tecnológicos, esto 
para identificar a los individuos o familias beneficiadas, y al mismo tiempo, para comprobar que recibieran la ayuda prometida y que la utilizaran para el fin establecido.

La política de redistribución focalizada universalizó la mercantilización de servicios, donde la capacidad adquisitiva para pagar, por ejemplo, paquetes básicos de salud o educación es la que determinaría la calidad del servicio comprado (Coraggio, 2003: 61).

De esta manera, el Estado de bienestar buscó homogenizar los estilos de vida que fueron definidos a través de las jerarquías establecidas por la igualdad de posiciones y articuladas al mercado laboral.

Entretanto, en el nuevo régimen de bienestar neoliberal se ha penalizado a los que no tienen propiedad, como los pobres, porque algunos de los subsidios estatales se canalizaron a las empresas de servicios privados que beneficiaron a las familias de ingresos medios y altos; sin embargo, esta situación se presentó más en los países desarrollados puesto que en los países en vías de desarrollo la mayoría de la población tiene bajos ingresos (Lo Vuolo, Raventós y Yanes, 2011: 271).

En América Latina, el modelo de industrialización, basado en la sustitución de importaciones con una regulación estatal importante, no pudo garantizar los derechos sociales de manera universal, limitándose a segmentos de la población dejando sin cobertura a otros grupos sociales, como por ejemplo, los sindicatos de obreros y de burócratas (González Marín, 2002). En el modelo económico neoliberal, la política social dejó de buscar la redistribución del ingreso, dejando de lado la idea de desarrollo, la que sustituyó por la de competitividad y desregulación estatal para que al final se centrara sólo en el combate a la pobreza. Por tal motivo, los programas estatales de asistencia social fueron programas de transferencias condicionadas que partían del siguiente supuesto: “(...) los pobres no se conducen de manera racional, no saben tomar decisiones y por ello hay que guiarlos, condicionarlos y, llegado el momento, castigarlos" (Lo Vuolo, Raventós y Yanes, 2011: 278). En otras palabras, buscan mediante la coerción estatal la creación de nuevos comportamientos entre los beneficiados, supuestamente para el cumplimiento de los objetivos de los diferentes programas.

Los programas de transferencias condicionadas son focalizados y dirigidos a las familias y no a las personas, con montos monetarios pequeños que no cubren las insuficiencias de ingresos, además de que no han sido diseñados como derechos porque son transitorios (Lo Vuolo, Raventós y Yanes, 2011: 277-280; Gordon, 1992).

El riesgo de que algunas familias queden fuera de los programas de transferencias condicionadas por incumplimiento, las convertiría en "clases 
peligrosas" porque podrían integrarse a las actividades ilícitas o criminales, según el punto de vista de algunos gobiernos neoliberales (Wacquant, 2009: 13-28). En este contexto, el paso del riesgo al peligro significaría que los hogares vulnerables, situación en que los mantienen los programas de transferencias condicionadas, se convertirían en parte de los objetivos de las estrategias gubernamentales de criminalización de la pobreza y la miseria (Wacquant, 2004: 11-19).

Insisto, en el modelo del Estado de bienestar, los riesgos provienen de la marcha de la economía capitalista, que en determinado momento, pueden afectar el principio organizativo de la igualdad de las posiciones. Ahora, en el modelo de la igualdad de las oportunidades, el riesgo se individualiza y se transforma en un peligro cuando es criminalizado por el Estado (Castel, 1992: 287). De esta manera, la pérdida involuntaria del empleo es la causa principal de la inseguridad económica y social, es criminalizada por el Estado neoliberal y lo que impide enfocar el problema desde la perspectiva de los derechos ciudadanos (Gámir 1997: 50-53). Sin embargo, el enfoque de la renta básica universal ha intentado rescatar los derechos ciudadanos al destacar que el desempleo no es cíclico, ni el empleo es por tiempo indefinido, es transitorio e inestable. Por eso, la renta básica universal no es un subsidio o subvención condicionada ni presupone la satisfacción de algún requisito, como el demostrar un determinado grado de pobreza, porque resulta ser incondicional y universal (Bertomeu y Raventós, 2006: 20-21).

Los programas de transferencias condicionadas buscan el control social de algunos segmentos de la población pobre, considerada como un problema en un contexto de inseguridad social que en realidad es una manifestación del fin de la sociedad del empleo (Mitjavila y Vecinday, 2011: 80-81). En consecuencia, desde la racionalidad derivada del control social, los asistidos son identificados mediante el uso de técnicas cuantitativas, que sirven para contarlos y clasificarlos, lo que genera información usada para su vigilancia de acuerdo con la lógica de la inclusión/exclusión (Banegas, 2008). Por lo tanto, el riesgo de quedar fuera del programa de asistencia social se manifiesta mediante la culpabilización de la víctima, lo que a su vez apoya el discurso que identifica el riesgo con los comportamientos no deseables (Mitjavila y Vecinday, 2011: 84-85). 
El Estado mexicano tuvo rasgos autoritarios porque ejerció un tutelaje sobre los derechos sociales de los grupos que desarrollaban sus actividades, tanto en la producción industrial como en la administración pública. Éstos estuvieron organizados en un partido político hegemónico. Por tal motivo, el Estado mexicano fue caracterizado como social autoritario (De la Garza, 1988).

La transformación posterior del Estado mexicano fue resultado de cambios en el modelo económico que se expresaron a través del desmantelamiento de los esquemas estatales de subsidios y transferencias generalizadas, tanto a la producción agrícola como al consumo. Por ejemplo, a partir de 1995 se establecieron los programas de transferencias condicionadas monetarias de manera focalizada como el Programa de Apoyos Directos al Campo (PROCAMPO), el Programa de Empleo Temporal (PET) y el Programa de Educación, Salud y Alimentación (PROGRESA), este último fue creado en agosto de 1997, sin embargo, en 2002 cambió de nombre a Programa de Desarrollo Humano Oportunidades (Lustig, 2010: 295-306).

Lo anterior también fue resultado de la austeridad fiscal adoptada por el gobierno mexicano en la década de los ochenta, ésta fue favorable a la creación de nuevos programas sociales. En este contexto, en 1988 surgió el primer programa de asistencia social focalizada, llamado Programa Nacional de Solidaridad (PRONASOL).

Desde un punto de vista general, el PRONASOL se transformó en el primer programa estatal que introdujo el modelo de la igualdad de oportunidades porque el Estado debería de proveer las capacidades necesarias a los beneficiados para mejorar su situación de pobreza extrema (Villarespe, 2001; Banegas, 2008: 311).

La orientación focalizada del PRONASOL permitió su división en los siguientes subprogramas: Solidaridad para el bienestar social, que incluía aspectos de salud, alimentación, educación, vivienda, servicios básicos y la expedición de títulos de propiedad privada del suelo, donde los pobres habían edificado su vivienda. Solidaridad para el desarrollo regional, que implicaba construcción de infraestructura, sobre todo de carreteras en regiones específicas y solidaridad para la producción, así como la creación de oportunidades de empleo mediante el desarrollo de capacidades a través del apoyo crediticio para el establecimiento de microempresas (Ordóñez, 2002: 203-213). 
La transformación del PRONASOL a PROGRESA tuvo como propósito abandonar el compromiso gubernamental de producción de infraestructura pública para los pobres de las ciudades y del campo, dejando de lado la entrega de un apoyo específico como tortilla o leche subsidiada para el posterior establecimiento de apoyos monetarios directos a las familias beneficiadas y enfocándose sólo en los pobres del campo y no de la ciudad (Hernández, 2008: 30). Además, desde la racionalización económica del gobierno neoliberal, el PROGRESA debería de tener una mayor cobertura en las áreas rurales marginadas donde las transferencias monetarias no se convirtieran en subsidios generalizados y pudieran beneficiar a los que no eran considerados pobres extremos como supuestamente sucedía en las ciudades. ${ }^{6}$

Las familias beneficiadas fueron seleccionadas de acuerdo con características socioeconómicas (número de integrantes de la familia, miembros que trabajan y aportan al ingreso familiar, ingreso promedio, escolaridad, tipo de vivienda y disponibilidad de servicios básicos), que además deberían contar con el apoyo de la comunidad, es decir, que los excluidos del PROGRESA tendrían que aceptar la inclusión de algunos de sus vecinos. Los apoyos durarían tres años con la posibilidad de una prórroga que dependía del cumplimiento de las familias con lo relacionado al envío de sus hijos a la escuela básica y a las visitas periódicas al médico para mejorar su alimentación (Levy, 1992).

El cambio de PROGRESA a Programa de Desarrollo Humano Oportunidades ${ }^{7}$ sólo fue para ampliar el número de familias beneficiadas, se integraron algunas familias pobres de las zonas urbanas y se apoyaría el acceso a la educación media superior, conservando la focalización en los mismos componentes de PROGRESA: educación, salud y alimentación. Las transferencias monetarias seguirían condicionadas a que los niños del hogar beneficiado asistieran a la escuela de manera regular (Esquivel, Lustig y Scott, 2011: 270-271).

Se buscaba que el Programa de Desarrollo Humano Oportunidades tuviera un impacto a largo plazo en la formación de capital humano, lo que

6 La focalización también ha significado que varias localidades donde habitan poblaciones en situaciones de pobreza y miseria no sean incluidas en el PROGRESA (Véase Badillo, 2009).

7 En México, en el año 2000, el cambio de nombre del programa de asistencia social focalizada coincide con la alternancia partidista en la presidencia después de más de 70 años de dominio del partido hegemónico (Partido Revolucionario Institucional, PRI) por parte del Partido Acción Nacional (PAN). El entonces presidente de la alternancia, Vicente Fox Quezada (2000-2006), consideró que la pobreza era resultado del rezago educativo de los individuos, lo que reproducía los bajos salarios y los trabajos precarios, afectando a los pobres también en su salud y alimentación (Calderón, 2007: 289-290). 
resultaba importante en el modelo de igualdad de oportunidades, donde los conocimientos y habilidades ahora justificaban la desigualdad social (Cogco, Rodríguez y Pérez, 2011:32-33). El principal mecanismo tecnológico y operativo de dicho programa para realizar las transferencias monetarias a las familias beneficiadas fue un holograma. A cada familia se le entregó una plantilla con varios hologramas y cuando se le otorgaba el dinero en efectivo se le pegaba uno de ellos en el recibo (Hernández, 2008: 49-50).

La idea de corresponsabilidad no significaba organización colectiva autónoma por parte de las familias beneficiadas, sino que los apoyos fueran vistos como resultado del esfuerzo particular de la familia para lograr su bienestar. Se recibía el apoyo monetario para la alimentación; por ejemplo, cuando cumplía con los compromisos relacionados con la salud, tales como la asistencia a las consultas preventivas y de vigilancia nutricional. Esto se registraba cada mes en las unidades de salud. Al mismo tiempo, en cuanto a la educación, la asistencia escolar se registraba para garantizar que las becas se entregaran a los estudiantes si éstos habían asistido a clases durante el mes (Hernández, 2008: 62-63).

Este programa de transferencia condicionada fue la base para establecer tres mediciones de la pobreza en México ${ }^{8}$ : pobreza alimentaria, que incluye los hogares que no pueden adquirir una canasta alimentaria básica a pesar de que gastaran todo su ingreso en ello; la pobreza de capacidades, que incluye la no adquisición de la canasta alimentaria básica ni los servicios de salud y educación; la pobreza de patrimonio, que implica la no adquisición de la canasta alimentaria, los servicios de salud y educación, una vivienda ni acceso al transporte público o vestido (Céspedes, 2011: 56). En México, al considerar al ingreso como una variable para explicar la pobreza, éste pierde relevancia porque el ingreso y el gasto coinciden en los grupos pobres, lo que ha provocado que su capacidad de ahorro y acumulación sea nula (Cortés, 2010: 79).

\section{Características de la sociedad mexicana fragmentada}

La fragmentación de una sociedad se puede observar mediante un acceso diferenciado a las protecciones sociales necesarias para la reproducción de los diversos grupos sociales. Por tal motivo, “(...) en América Latina nos

$8 \quad$ La Ley General de Desarrollo Social fue publicada el 20 de enero de 2004 en el Diario Oficial de la Federación. Dicha ley estableció que un Consejo Nacional de Evaluación de la Política de Desarrollo Social utilizaría la metodología de los tres niveles de pobreza para su medición (Céspedes, 2011: 59-60). 
encontramos con modernas clínicas privadas, hospitales públicos y centros de salud, hay además seguridad privada, seguridad pública, y no seguridad, o también sistemas de pensiones privadas, mínimas garantizadas por el Estado..." (Saraví, 2009: 26). En otras palabras, la fragmentación social significa exclusión o acceso limitado a las instituciones de bienestar o una integración diferenciada debido a la segmentación de los instrumentos de la política económica y social. Lo anterior ha creado una nueva desigualdad social que tiene una interpretación más cualitativa que cuantitativa (Ibarra, 2013: 57-76), sobre todo porque se ha identificado la fragmentación social con la desintegración de los lazos de solidaridad, lo que ha sido favorable a una gradual individualización de las relaciones sociales, es decir, el bienestar se ha vuelto un asunto personal o individual, y en consecuencia, se acaba midiendo sólo por el monto del ingreso y por la capacidad de consumo (Revilla, Jefferys, Tovar Martínez, 2013: 396). El desmantelamiento del Estado social autoritario mexicano impulsó la fragmentación de la sociedad mediante la expansión de la vulnerabilidad para los desempleados y subempleados, en particular por la ausencia o el acceso limitado a las protecciones sociales. ${ }^{9}$

Por otra parte, la vulnerabilidad social ha sido fomentada por la ausencia de una política redistributiva, misma que fue sustituida por programas de transferencias condicionadas organizados bajo el modelo de la igualdad de oportunidades donde la educación es un factor de desarrollo desigual entre los individuos. Finalmente, esto ha reproducido la fragmentación social, pues existe un acceso diferenciado o limitado a las diferentes opciones educativas (Mingione, 1993: 568-569).

En consecuencia, la fragmentación social también se ha manifestado mediante un aumento de los empleos informales. Por ejemplo, en México, en el mes de marzo de 2012, el trabajo informal ocupó a 13 millones 757 mil personas, es decir, el 28.76 por ciento de la población estaba ocupada en unidades económicas que no son agropecuarias sin registros contables y que solamente funcionan con los recursos propios del hogar o del individuo. Sin embargo, en el mismo mes de marzo de 2012, el número de desempleados fue de 2 millones 300 mil personas. Lo que se debe destacar es que el desempleo afectó más a la población con un mayor nivel educativo, el 75.5 por ciento de los desocupados tenía una instrucción superior al nivel secundaria (González, 2012).

9 En México existe un acceso desigual a las oportunidades porque también la movilidad social es casi nula (Serrano y Torche, 2010: 7-8). 
En México, la estructura organizativa de los intereses corporativos, bajo el autoritarismo estatal, no sólo influyó en la limitación de la capacidad organizativa de la sociedad mexicana (Zermeño, 1996: 14-22), también en la segmentación del mercado de trabajo caracterizado por la existencia de trabajadores con empleos estables y protegidos por la seguridad estatal; mientras otros eran mal remunerados y sin seguridad social y relegados al sector menos productivo de la economía (Bértola y Ocampo, 2013: 298-306). A lo largo del siglo XX, esta situación favoreció la reproducción de desigualdades que se caracterizaron por niveles de ingreso, educación y salud semejantes a los existentes en países desarrollados para los privilegiados y que convivieron con niveles de vida parecidos a los que se observan en países como Haití, Senegal y Bangladesh para una población empobrecida con las reformas económicas neoliberales (Scott, 2012: 33-34).

Desde un punto de vista urbano, la desigualdad social se expresó como pobreza urbana distribuida en las grandes ciudades mediante la construcción ilegal de vivienda en sus periferias donde la irregularidad significaba ausencia de servicios públicos y también la no posesión del título de propiedad sobre el suelo. Sin embargo, el bienestar de sus pobladores se identificó con la introducción paulatina de los servicios públicos y con la transformación de la posesión del suelo en propiedad a través de la intervención estatal. Ésta fue la base de la estabilidad social urbana durante el régimen del partido hegemónico debido a que sus beneficiarios en épocas de elección se convirtieron en votos a favor de dicho régimen (Azuela, 1989; Padilla y Ribbeck, 2009: 27-49), lo que paulatinamente se fue modificando por la disolución del régimen de partido único que dio paso a la alternancia en el poder ejecutivo en el año 2000. Gracias a ello, se introdujo la visión focalizada en el desarrollo urbano a través del programa Hábitat en 2003, abarcando acciones tan diversas como el cuidado infantil, la regularización de la tenencia de la tierra, la remodelación de los espacios públicos, y en esta última acción, por ejemplo, se gastó el 88 por ciento de su presupuesto en 2010 (Ordoñez, 2012: 98-107).

La cobertura del programa Hábitat llegó solamente al 20 por ciento de los hogares pobres y a nivel estatal se logró el 100 por ciento en Baja California y Baja California Sur, mientras que en el Distrito Federal apenas llegó al 3 por ciento en 2010. Esto significó que las entidades más urbanizadas fueron las que menos atención recibieron por parte del programa (Ordoñez, 2012: 108-113), lo que favoreció la reproducción de la desigualdad social en el territorio de manera fragmentada (Díaz, 2006: 47-48).

No obstante, el debilitamiento de la estructura corporativa estatal mexicana, desde un punto de vista sociológico, provocó una fragmentación so- 
cial identificada más con la desarticulación, pauperización, desidentidad, anomia, es decir, como un desorden social (Zermeño, 1996: 30; Zermeño, 2005: 24-39; Ravelo, 2011) en un contexto de economía estancada o de bajo crecimiento (Puyana y Romero, 2009).

La modernidad económica neoliberal tampoco resultó favorable a la creación de mecanismos de participación ciudadana sólidos (Tamayo, 2010: 21-28) ni fortaleció el orden legal a pesar de que la ciudadanía intentó definirse por los derechos políticos, más que por los sociales (Escalante, 1992: 289). Siguió prevaleciendo, en consecuencia, un orden convencional segmentado definido por lealtades particulares de tipo comunitario o clientelista (Escalante, 1999: 82-83).

En México, la fragmentación social ha puesto en evidencia que existe un acceso diferenciado a la justicia legal que depende más de las posiciones de privilegio socioeconómico (Durand, 2010: 23). Desde el punto de vista de los derechos ciudadanos, la fragmentación social mexicana se observa mediante la presencia de una situación de excepción, donde no se garantiza la aplicación de la ley a todos los gobernados, ésto reproduce las situaciones de injusticia que han creado un estado de ilegalidad permanente (Durand, 2010: 34; Agamben, 2006). En consecuencia, en el caso mexicano, la vulnerabilidad social significa ciudadanía débil sin protecciones estatales que han perdido su carácter universal a favor del asistencialismo focalizado (Esping-Andersen y Palier, 2010: 7-18; Tilly, 2000).

De acuerdo con el modelo de la igualdad de oportunidades aplicado en México se consideró que las familias en pobreza extrema requerirían de la formación de capital humano a través de la educación de sus hijos; pero en un contexto de crecimiento de las actividades económicas informales, sus capacidades y habilidades no son importantes ante la escasez de empleo formal y debido a los bajos salarios. Si se considera que la mayoría de las actividades económicas informales son ilegales, entonces se ha creado otra situación de excepción y vulnerabilidad pues cuando la ley se aplica es para penalizar y castigar a algunos grupos sociales (Durand, 2010: 37).

La vulnerabilidad social mexicana es resultado de una ciudadanía precaria, lo que ha puesto en evidencia la contradicción existente entre la igualdad formal y las desigualdades sociales reales donde no existen mecanismos estatales de bienestar con un carácter universal. 


\section{Reflexión final}

El significado sociológico del modelo de la igualdad de oportunidades, se ha expresado a través del desarrollo de las potencialidades individuales y logrado a través de la formación educativa, lo que supuestamente permite competir en la economía del conocimiento. En consecuencia, el éxito o fracaso es individual y depende de que los conocimientos y habilidades que el individuo posee le sirvan para conseguir un empleo estable y bien remunerado. Se compite en el mercado de trabajo mediante los méritos o calificaciones y dentro de esta lógica, el Estado ha diseñado un conjunto de programas de reinserción laboral o de asistencia social para los vulnerables, buscando dotarlos de habilidades que les ayuden a competir por un empleo que ha dejado de ser estable y de larga duración. Sin embargo, no se ha entendido que los individuos son vulnerables porque el Estado ha dejado a un lado su función social: la de proteger a la sociedad de las consecuencias negativas generadas por la dinámica económica capitalista y que hacen más evidente el divorcio entre la igualdad formal y las desigualdades reales, aceptadas estas últimas por la ideología del capital humano.

Los programas sociales de transferencias condicionadas se han orientado por la racionalidad económica de la eficiencia y han reorganizado, al mismo tiempo, los comportamientos de las familias beneficiadas para cumplir con los objetivos de la focalización (Olson, 1992). Se parte, en consecuencia, de otro supuesto: el bienestar individual agregado provocaría de manera automática una situación de bienestar social.

Por otra parte, los dispositivos del bienestar focalizado se basan en sistemas tecnológicos de control social como las bases de datos particulares de las familias beneficiadas, tarjetas bancarias para depositar la ayuda monetaria, hologramas, registros de visitas al médico y de asistencia escolar, entre otros. Este hecho también significa que el manejo de la información personal de los individuos considerados como vulnerables mediante los artefactos tecnológicos, es una nueva manera de vigilar desde el Estado el cumplimiento de las metas del programa en particular y de sancionar, al mismo tiempo, a los beneficiados que no cumplen a través de la exclusión de ayuda o asistencia estatal (Lyon, 2004: 1-11).

Finalmente, la idea de vulnerabilidad se refiere a un proceso de pérdida de importancia del modelo de la igualdad de oportunidades donde se ha generalizado la precariedad laboral y el desempleo; sin embargo, su sustitución por la noción de pobreza, entendida como carencia de bienes 
y servicios, es para destacar sólo la existencia de un problema de consumo ocasionado por la falta de ingresos.

\section{Bibliografía}

About, I., y V. Denis, 2011, Historia de la identificación de las personas, Barcelona, Ariel.

Adelantado, J., J. Noguera y X. Rambla, 2000, “El marco de análisis: las relaciones complejas entre estructura social y políticas sociales", en José Adelantado (coord.), Cambios en el Estado del Bienestar. Políticas sociales y desigualdades en España, Barcelona, Icaria-Universidad Autónoma de Barcelona.

Agamben, G., 2009, What is an apparatus? And other essays, California, Stanford University Press.

Agamben, G., 2006, Homo sacer. El poder soberano y la nuda vida. Valencia, Pre-Textos.

Althusser, L., 2011, La filosofía como arma de la Revolución, México, Siglo XXI Editores.

Azuela, A., 1989, La ciudad, la propiedad privada y el derecho, México, El Colegio de México.

Badillo, M., 2009, Morir en la miseria, México, Editorial Océano.

Banegas, I., 2008, “El cambio en la administración de los riesgos sociales: política social y transformación del Estado", Estudios Sociológicos 36 (77), pp. 287-319.

Banerjee, A. y E. Duflo, 2011, Poor Economics. A Radical Rethinking of the Way to Fight Global Poverty, USA, Public Affairs.

Bértola, L. y J. A. Ocampo, 2013, El Desarrollo Económico de América Latina desde la Independencia, México, FCE.

Bertomeu, J. y D. Raventós, 2006, “El derecho de existencia y la renta básica de ciudadanía: una justificación republicana”, en Gerardo Pisarello y Antonio de Cabo (eds.), La renta básica como nuevo derecho ciudadano, Madrid, Trotta.

Braunstein, N., 2012, El inconsciente, la técnica y el discurso capitalista, México, Siglo XXI Editores.

Calderón, G., 2007, La pobreza en México, México, Gernika. 
Castel, R., 2010, Las transformaciones del trabajo, de la producción social y de los riesgos en un período de incertidumbre, Buenos Aires, Siglo XXI Editores.

Castel, R., 2004a, La inseguridad social ¿Qué es estar protegido?, Buenos Aires, Manantial.

Castel, R., 2004b, “Encuadre de la exclusión”, en Saül Karsz (coord.), La exclusión bordeando sus fronteras, Barcelona, Gedisa.

Castel, R., 2004c, Las metamorfosis de la cuestión social. Una crónica del salariado, Buenos Aires, Paidós.

Castel, R. y C. Haroche, 2003, Propiedad privada, propiedad social, propiedad de sí mismo. Conversaciones sobre la construcción del individuo moderno, Rosario, Homo Sapiens Ediciones.

Castel, R., 2001, “¿Por qué la clase obrera ha perdido la partida?”, Archipiélago (48), pp. 37-45.

Castel, R., 1995, "De la exclusión como estado a la vulnerabilidad como proceso", Archipiélago (21), pp. 27-36.

Castel. R., 1992, "From Dangerousness to Risk", en Graham Burchell, Colin Gordon y Peter Miller (eds.), The Foucault Effect. Studies in Governmentality with Two Lectures by and a Interview with Michel Foucault, USA, The University of Chicago Press.

Ceballos, H., 2005, Foucault y el Poder, México, Ediciones Coyoacán.

CEPAL, 1995, Focalización y Pobreza, México, ONU.

Céspedes, J., 2011, Pobreza y escasez de agua en el México del Siglo XXI, México, Novum.

Cogco, A., M. Rodríguez y J. Pérez, 2011, “Las transferencias condicionadas y la atención de la pobreza en México", en Oscar Alfonso Martínez, Claudia Campillo y Adolfo Rogelio Cogco (coords.), Las transferencias condicionadas en Iberoamérica. Un acercamiento a casos en México, Brasil y España, México, Universidad Iberoaméricana-Universidad Autónoma de Nuevo León-Universidad Autónoma de Tamaulipas.

Collins, R., 1989, La sociedad credencialista. Sociología histórica de la educación y la estratificación, Madrid, Akal. 
Coraggio, J.L., 2003, Política social y economía del trabajo: Alternativas a la política neoliberal para la ciudad, Toluca, El Colegio Mexiquense.

Cortés, F., 2010, “Pobreza, desigualdad en la distribución del ingreso y crecimiento económico, 1992-2006", Fernando Cortés y Orlandina de Oliveira (coords.), Desigualdad Social. T. V., México, El Colegio de México.

De la Garza, E., 1988, Ascenso y crisis del Estado social autoritario, México, Colegio de México.

Delcourt, L., 2010, “La intervención del Estado. El porqué de las políticas sociales", en Laurent Delcourt (coord.), El regreso de la intervención del Estado. Hacia dónde van las políticas sociales, Madrid, Editorial Popular.

Díaz, F., 2006, “Globalización, espacio urbano y fragmentación social. Los muros de la ciudad”, Gabino Ponce Herrero (Ed.), La Ciudad Fragmentada. Nuevas formas de hábitat, Alicante, Publicaciones Universidad de Alicante.

Díaz-Salazar, R., 2011, Desigualdades internacionales ¡Justicia ya; Barcelona, IcariaAsaco.

Doyal, L. e I. Gough, 1994, Teoría de las necesidades humanas, Madrid, Icaria-FUHEM.

Dubet, F., 2011, Repensar la justicia social. Contra el mito de la igualdad de oportunidades, Buenos Aires, Siglo XXI editores.

Dubet, F., 2000, Les Inégalités Multipliées, Paris, Éditions de l’Aube.

Durand, V., 2010, Desigualdad social y ciudadanía precaria ¿Estado de excepción permanente? México, Instituto de Investigaciones Sociales de la Universidad Nacional Autónoma de México-Siglo XXI Editores.

Durkheim, E., 1993, La división del trabajo social T. I y II. México, Planeta Agostini.

Elías Salazar, M. A., 2013, El concepto vulnerabilidad sociodemográfica. Elementos que ayudan a entender los alcances de la crisis actual, México, Unidad Académica de Ciencias Sociales, UAZ-Taberna libraria editores.

Escalante, F., 1999, La democracia mafiosa, México, Reflexiones sobre el Cambio, A. C.

Escalante, F., 1992, Ciudadanos Imaginarios. Memorial de los afanes y desventuras de la virtud y apología del vicio triunfante en la República Mexicana-Tratado de Moral Pública, México, El Colegio de México. 
Esping-Andersen, G. y B. Palier, 2010, Los tres grandes retos del Estado del bienestar, Barcelona, Ariel.

Esping-Andersen, G., 2001, “Burócratas o arquitectos? La reestructuración del Estado benefactor en Europa”, en Ulrich Beck, et al., Presente y futuro del Estado de Bienestar: el debate europeo, Buenos Aires, SIEMPRO-Miño y Dávila.

Esping-Andersen, G., 1993, Los Tres Mundos del Estado de Bienestar, Valencia, Institució Valenciana D’Estudis i Investigació Valencia-Generalitat Valenciana Diputació Provincial de Valencia.

Esquivel, G., N. Lustig y J. Scott, 2011, “Un decenio de reducción de la desigualdad en México ¿Fuerzas del mercado o acción del Estado?, en Luis F. López-Calva y Nora Lustig (comps.), La disminución de la desigualdad en América Latina ¿Un decenio de progreso?, México, Fondo de Cultura Económica.

Field, J., 2003, Social Capital, Londres, Routledge.

Foucault, M., 2009,Vigilar y castigar. Nacimiento de la prisión, México, Siglo XXI Editores.

Gámir, L., 1997, La economía del bienestar, Madrid, Biblioteca Nueva-Fundación Argentaría.

González Marín, M. L., 2002, La industrialización en México, México, Instituto de Investigaciones Económicas UNAM-Miguel Ángel Porrúa.

Gónzalez, I., 2012, “Con empleo informal, 13.7 millones". www.eluniversal.com. mx/primera/39291.html (Consultado el 21 de marzo de 2012).

Gordon, C., 1992, “Gobernmental Rationality: An Introduction”, en Graham Burchell, Colin Gordon y Peter Miller (eds.), The Foucault Effect. Studies in Governmentality with Two Lectures by and a Interview with Michel Foucault, USA, The University of Chicago Press.

Gowan, P., 2000, La apuesta por la globalización. La geoeconomía y la geopolítica del imperialismo euro-estadounidense, Madrid, Ediciones Akal.

Griffin, K., 2001, “Desarrollo humano: origen, evolución e impacto”, en Pedro Ibarra y Koldo Unceta (coords.), Ensayos sobre el desarrollo humano, Barcelona, Icaria.

Hernández, D., 2008, Historia de Oportunidades. Inicio y cambios del programa, México, Fondo de Cultura Económica. 
Herrera, M. y B. Castón, 2003, Las políticas sociales en las sociedades complejas, Barcelona, Gedisa.

Honneth, A., 2009, Crítica del poder. Fases en la reflexión de una Teoría Crítica de la sociedad, Madrid, Machado Libros.

Ibarra, D., 2013, La crisis inacabada, México, Cátedra Extraordinaria Raúl Prebisch Facultad de Economía, UNAM.

Le Grand, J., 2001, “¿De caballeros a pícaros? Políticas públicas e incentivos de mercado", en Ulrich Beck, et al., Presente y futuro del Estado de Bienestar: el debate europeo, Buenos Aires, SIEMPRO-Miño y Dávila.

Levy, S., 1992, La pobreza en México, México, Mimeo.

Lo Vuolo, R., D. Raventós y P. Yanes, 2011, “La crisis económica, los subsidios condicionados y la renta básica", en David Casassas y Daniel Raventós (eds.), La renta básica en la era de las grandes desigualdades, España, Montesinos.

Lustig, N., 2010, “El impacto de 25 años de reformas sobre la pobreza y la desigualdad", en Nora Lustig (coord.), Crecimiento Económico y Equidad T. IX, México, El Colegio de México.

Lyon, D., 2004, Surveillance alter September 11, USA, Polity.

Marshall, T. H. y T. Bottomore, 1998, Ciudadanía y clase social, Madrid, Alianza.

Mendiola Gonzalo, I., 2009, “La Bio(tanato) política moderna y la producción de disponibilidad", en Ignacio Mendiola Gonzalo (ed.), Rastros y rostros de la biopolítica. Barcelona, Anthropos.

Mingione, E., 1993, Las sociedades fragmentadas. Una sociología de la vida económica. Más allá del paradigma del mercado, Madrid, Ministerio de Trabajo y Seguridad Social.

Mitjavila, M., y L. Vecinday, 2011, “El enfoque de riesgo como dispositivo individualizador en el campo social", en Belén Lorente Molina (ed.), Transformaciones del Estado Social. Perspectivas sobre la intervención social en Iberoamérica, Buenos Aires, Miño y Dávila

Montagut, T., 2004, Política Social. Una introducción, Barcelona. Ariel.

Navarro, V., 2000, Globalización económica, poder politico y Estado del bienestar, Barcelona, Ariel. 
Neffa, J.C., 2010, “Naturaleza y significación del trabajo/empleo precario”, en Mariana Busso y Pablo Pérez (coords.), La corrosión del trabajo. Estudios sobre informalidad y precariedad laboral, Buenos Aires, Miño y Dávila editores.

Offe, C., 1990, Contradicciones en el Estado del bienestar, México, CNCA-Alianza.

Olson, M., 1992, La lógica de la acción colectiva. Bienes públicos y la teoría de grupos, México, Limusa Noriega Editores.

Ordóñez, G., 2002, La Política social y el combate a la pobreza en México. México, SEDESOL-UNAM.

Ordóñez, G., 2012, “La estrategia para la superación de la pobreza urbana en los gobiernos de la alternancia (2000-2010)”, Gerardo Ordoñez Barba (coord.), La Pobreza Urbana en México: Nuevos enfoques y retos emergentes para la acción pública, México, COLEF-Juan Pablos Editor.

Padilla, S. y E. Ribbeck, (2009), “Colonias populares en la ciudad de México. Urbanismo informal y autoconstrucción”, en Sergio Padilla Galicia (comp.), Urbanismo Informal, México, UAM-A.

Peña, C., 2010, El concepto de cohesión social, México, Ediciones Coyoacán.

Pisarello, G., 2007, Los derechos sociales y sus garantías. Elementos para una reconstrucción, Madrid, Editorial Trotta.

Polanyi, K., 2003, La gran transformación. Los orígenes políticos y económicos de nuestro tiempo, México, Fondo de Cultura Económica.

Putnam, R., 2003, El declive del capital social. Un estudio internacional sobre las sociedades y el sentido comunitario, Barcelona, Galaxia Gutenberg-Círculo de Lectores.

Puyana, A. y J. Romero, 2009, México. De la crisis de la deuda al estancamiento económico, México, El Colegio de México.

Puyol, A., 2010, El sueño de la igualdad de oportunidades. Crítica de la ideología meritocrática, Barcelona, Gedisa Editorial.

Ravelo, R., 2011, El narco en México. Historia e historias de una guerra, México, Grijalbo.

Reed, I. A., 2011, Interpretation and Social Knowledge. On the use of Theory in the Human Sciences, USA, The University of Chicago Press. 
Revel, J., 2009, Diccionario Foucault, Buenos Aires, Nueva Visión.

Revilla, J. C, S. Jefferys y F. J Tovar Martínez, 2013, “Collective identities in the age of restructuring: Old and new class, space and community-based identities in six European regions", International Sociology 28(4), pp. 391-408.

Rifkin, J., 2010, El fin del trabajo. Nuevas tecnologías contra puestos de trabajo: El nacimiento de una nueva era, Barcelona, Paidós.

Saraví, G., 2009, Transiciones vulnerables. Juventud, desigualdad y exclusión en México, México, CIESAS.

Serrano, J. y F. Torche, 2010, Movilidad social en México. Población, desarrollo y crecimiento, México, Centro de Estudios Espinosa Yglesias.

Scott, J., 2012, “Protección social universal”, Fausto Hernández Trillo (ed.), Seguridad social universal. Retos para su implementación en México, México, CIDE.

Silveira, H., e I. Rivera, 2009, “La biopolítica contemporánea ante los flujos migratorios y el universo carcelario. Una reflexión sobre el regreso de los 'campos' en Europa", en Ignacio Mendiola Gonzalo (ed.), Rastros y rostros de la biopolítica, Barcelona, Anthropos.

Simmel, G., 2011, El pobre, Madrid, Sequitur.

Sorensen, G., 2011, La transformación del Estado. Más allá del mito del repliegue, México, Tirant lo Blanch.

Sotelo, I., 2010, El Estado Social. Antecedentes, origen, desarrollo y declive, Madrid, Editorial Trotta.

Steger, M. B. y R. K. Roy, 2011, Neoliberalismo una breve introducción, Madrid, Alianza Editorial.

Swaan, A., 1992, A cargo del Estado, Barcelona, Ediciones Pomares-Corredor.

Tamayo, S., 2010, Crítica de la ciudadanía, México, Universidad Autónoma Metropolitana Azcapotzalco-Siglo XXI Editores.

Tilly, C., 2000, La desigualdad persistente, Buenos Aires, Manantial.

Torche, F., 2010, "Cambio y persistencia de la movilidad intergeneracional en México", en Julio Serrano Espinosa y Florencia Torche (eds.), Movilidad social en 
México. Población, desarrollo y crecimiento, México, Centro de Estudios Espinosa Yglesias.

Villarespe, V., 2001, La solidaridad: Beneficiencia y Programas. Pasado y Presente del Tratamiento de la Pobreza en México, México, Instituto de Investigaciones Económicas de la Universidad Nacional Autónoma de México-Miguel Ángel Porrúa.

Wacquant, L., 2009, Castigar a los pobres. El gobierno neoliberal de la inseguridad social, Barcelona, Gedisa Editorial.

Wacquant, L., 2004, Punir les pauvres. Le Nouveau gouvernement de l'insécurité sociale, Paris, Agone.

Wacquant, L., 2000, Las cárceles de la miseria, Buenos Aires, Manantial.

Zermeño, S., 2005, La desmodernidad mexicana y las alternativas a la violencia y a la exclusión en nuestros dias, México, Océano.

Zermeño, S., 1996, La sociedad derrotada. El desorden mexicano del fin de siglo, México, Instituto de Investigaciones Sociales de la Universidad Nacional Autónoma de México-Siglo XXI Editores.

Recibido el 21 de agosto de 2013

Aceptado el 21 de marzo de 2014 